\title{
Hepatitis E Virus Infection in HIV Positive ART Naïve and Experienced Individuals in Nigeria*
}

\author{
Georgina N. Odaibo", David O. Olaleye \\ Department of Virology, College of Medicine, University of Ibadan, Ibadan, Nigeria \\ Email: "\#oreodaibo@hotmail.com
}

Received June $13^{\text {th }}, 2013$; revised June $30^{\text {th }}, 2013$; accepted July $10^{\text {th }}, 2013$

Copyright (C) 2013 Georgina N. Odaibo, David O. Olaleye. This is an open access article distributed under the Creative Commons Attribution License, which permits unrestricted use, distribution, and reproduction in any medium, provided the original work is properly cited.

\begin{abstract}
Background: Studies have shown Hepatitis E Virus to be a causative agent of acute and chronic hepatitis in severely immunocompromised patients such as organ transplant recipients and person with HIV infection. This study was designed to determine the burden of HEV infection among HIV positive individuals in Nigeria and the effect of HIV treatment on the burden of HEV infection among this group of patients. Methods: Aliquot of plasma samples collected for laboratory investigations such as CD4 enumeration, blood chemistry (AST, ALT, Creatine, Urea) were used to determine the presence of HEV IgG and IgM antibodies using commercially available ELISA. Samples analysed in the study were collected from 180 HIV positive individuals (90 ART naïve and 90 ART experienced) attending the ART clinic at the University College Hospital, Ibadan, Nigeria. Results: Twenty two of the $180(12.2 \%)$ samples were positive for either HEV IgG (20/180) or IgM (2/180). The rate of HEV IgG was higher among ART naïve individuals and the two IgM positive persons were ART naïve. There was no significant difference in the mean CD4 count and mean ALT between HEV seronegative and seropositive individuals $(\mathrm{P}=0.8$ and 0.2 respectively). Conclusions: The results of this study suggest the need to test for HEV infection in HIV positive individuals for the early diagnosis and proper management since HEV is known to be fulminant in the presence of underlying liver disease that is common among HIV infected persons. In addition, the use of ART may reduce the incidence of HEV infection in HIV positive persons.
\end{abstract}

Keywords: HEV Infection; HIV Positive; ART; Nigeria

\section{Background}

Viral hepatitis is a major cause of morbidity and mortality globally. Various viral agents including Hepatitis A, $\mathrm{B}, \mathrm{C}, \mathrm{D}, \mathrm{E}$ and $\mathrm{G}$ are known as causes of liver diseases such as cirrhosis, hepatocellular carcinoma and liver failure [1]. Hepatitis E disease is a self-limited feco-orally transmitted acute viral infection that occurs most frequently in epidemic forms [2]. The aetiology of the disease is Hepatitis E Virus (HEV), a non-enveloped RNA virus belonging to the genus hepevirus of the family Hepeviridae. The virus is transmitted from person to person

\footnotetext{
"Competing interest: We declare that we have no conflicting interest in the conduct of the study.

Authors' contribution: GNO and DOO conceived the idea of the study, GNO, DOO were involved in the collection and analysis of data, GNO supervised the laboratory investigations. GNO wrote the draft manuscript while both authors reviewed the final manuscript and approved the final version. DOO is the guarantor of the paper.

${ }^{\#}$ Corresponding author.
}

feco-orally, hence its transmission is highly associated with poor hygiene or sanitation [2-4]. The virus has also been found in animals such as pigs, rodents, deer, and the possibility of zoonotic transmission of the virus has been suggested [5-8].

The prevalence of HEV in human population varies from one geographic location to another with high mortality rates in some areas, especially among pregnant women and persons with immunodeficiencies including organ transplant recipients [9-12]. The reported prevalence of HEV infection reported from the USA and Western Europe ranges from one to five percent [13-15], while the rate in developing countries ranges from $10 \%$ to $100 \%$ in some population groups $[16,17]$. Labrique and colleagues [18] in a study in Bangladesh reported a prevalence of $22.5 \%$ and the rate in Egypt has been reported to be as high as $100 \%$ among some population groups [16]. Ola et al. [19] found a seroprevalence rate of $44 \%$ among Health Workers in Nigeria. 


\section{Objectives of the Study}

Recent studies have shown Hepatitis E Virus to be causative agent of acute and chronic hepatitis in severely immunocompromised patients such organ transplant recipients and persons with HIV infection [9,12]. This study was designed to determine the burden of HEV infection among HIV positive individuals in Nigeria and the effect of HIV treatment on the infection.

\section{Study Design}

\subsection{Study Population}

The study participants included 90 HIV positive antiretroviral drug naïve and $90 \mathrm{HIV}$ positive ART experienced individuals attending the ARV treatment clinic at the University College Hospital, Ibadan, Nigeria for HIV/ AIDS care and treatment. Only individuals who have been on ART for a minimum of one year were included among the ART experienced group. Ethical approval was obtained from the UI/UCH Ethical Review committee for the study.

\subsection{Laboratory Analysis}

Aliquot of plasma samples collected for laboratory investigations such as CD4 enumeration, blood chemistry (AST, ALT, Creatine, Urea.) were used to determine the presence of HEV IgG and IgM antibodies using commercially available Enzyme Immunoassay.

\subsection{Detection of HEV IgG}

The DIA. PRO HEV AB, a $3^{\text {rd }}$ generation EIA by Diagnostic Bioprobes (Milano, Italy) was used to test for the presence of HEV IgG. The assay was carried out according to manufacturer's recommendation. Briefly, $200 \mathrm{ul}$ of diluted sample (1:20) was added to respective wells coated with HEV specific antigens. After incubation at $37^{\circ} \mathrm{C}$ for $45 \mathrm{mins}$, wells of the reaction plates were washed and conjugate was added. Each reaction plate was washed again after incubation at 37, chromogen/substrate was then added and the OD value determined at $450 \mathrm{~nm}$ wavelength. The cut-off value was calculated and results interpreted as recommended by manufacturer.

\subsection{Detection of HEV IgM}

The HEV-IgM ELISA by Wantai Diagnostics, Beijing, China was used to detect the presence of HEV IgM in the plasma samples. The 96 wells polystyrene microwell is precoated with anti-human IgM. On addition of sample, bound HEV IgM was detected by use of recombinant HEV ORF2 antigen conjugated to the enzyme horseradish peroxidase. The assay procedure was carried out as recommended by the manufacturer. After addition of the stop solution, absorbance value for each of the wells was read at a dual wavelength of $450 / 630 \mathrm{~nm}$.

\section{Results}

The characteristics of the study population are shown in Table 1. Two-third of the patients attending the ART clinic during the period of sample collection were female. The mean age, mean CD4 and mean ALT of the participants were 39.4 years (range: 17 - 84), 351 cells/ul (range: 16 - 1565) and 27.0 (range: 4 - 212) respectively.

Overall, the rate of HEV infection (combined IgG and $\operatorname{IgM})$ found in this study is $12.2 \%(22 / 180)$. Twenty of the $180(11.1 \%)$ patients were positive for HEV IgG while $2(1.7 \%)$ were positive for IgM (Table 2). The prevalence of HEV IgG was higher among ART drug naïve $(13.3 \%)$ patients while the two individuals who were

Table 1. Demographic characteristics and some laboratory parameters of HIV positive patients tested for HEV infection.

\begin{tabular}{cccccccc}
\hline \multirow{2}{*}{ ART status } & $\begin{array}{c}\text { Mean age (years) } \\
{[\text { Range] }\{\text { SD }\}}\end{array}$ & \multicolumn{2}{c}{ Gender } & Mean CD4 (cells/ul) & $\begin{array}{c}\text { Mean ALT (IU/L) } \\
\text { [Range] }\{\mathrm{SD}\}\end{array}$ & $\begin{array}{c}\text { Average period on ART } \\
\text { (years) [Range }]\end{array}$ \\
\cline { 3 - 4 } ART naïve & $37[17-64]\{11.2\}$ & 28 & 62 & $259[16-1022]\{221.1\}$ & $29.3[1-132]\{25.9\}$ & Not applicable \\
ART exposed & $42[26-84]\{10.1\}$ & 32 & 58 & $443[26-1565]\{343.6\}$ & $24.8[4-212]\{36.7\}$ & $2(1-5$ years) \\
Overall & $39.4(17-84)\{10.9\}$ & 60 & 120 & $351(16-1565)\{302\}$ & $27.0(1-212)\{28\}$ & \\
\hline
\end{tabular}

Table 2. Prevalence of HEV IgG and IgM antibodies by ART statusamong HIV positive patients attending ART clinic at UCH, Ibadan, Nigeria.

\begin{tabular}{ccccc}
\hline ART status & No tested & HEV IgG No (\%) positive & HEV IgM No (\%) positive & Past and present HEV infection No (\%) positive \\
\hline ART naive & 90 & $12(13.3)$ & $2(2.2)$ & $14(15.6)$ \\
ART exposed & 90 & $8(8.9)$ & $0(00)$ & $8(8.9)$ \\
Total & 180 & $20(11.1)$ & $2(1.7)$ & $22(12.2)$ \\
\hline
\end{tabular}


positive for HEV IgM were also ART drug naïve with mean CD4 of 205 and mean ALT of 31. The prevalence of the infection was higher among female and those in the $\geq 60$ years age group followed by the 30 - 39 years age group (Table 3 ). The mean CD4 count among ART experienced individuals was higher than that of ART naïve $(P=0.004)$. However, there was no significant difference in the mean CD4 count among HEV negative HEV positive individuals $(\mathrm{P}=0.1)$. Overall, the mean ALT (IU/L) was lower among the HEV positive than HEV negative ART Naïve (18.4 vs 31.4; $\mathrm{P}=0.2)$ and ART experienced ( 20 vs $25 ; \mathrm{P}=0.7)$ individuals.

\section{Discussion}

Hepatitis E virus infection recently has been described as an emerging infection among patients with immunosuppressing conditions of such human immunodeficiency infection $[9,20,21]$. In this study we found a high rate (12.5\%) of HEV among HIV positive individuals attending an ART clinic in Nigeria. Although this rate is higher than the previously reported among similar populations in the industrialized countries $[9,15,22,23]$, it is lower than the rates of HEV infection reported among some population groups HEV endemic areas of Africa [17] and Asia $[10,18]$. Interestingly, the prevalence of HEV infection found in this study is lower than the previously reported rate of $44 \%$ among Health workers in Nigeria [19]. Although the reason for this difference is not clear, it has been suggested that "health care setting is a home for transmission of infection especially where running water and other materials for hand hygiene are lacking" $[19,24]$. Nosocomial transmission of HEV infection has also been reported [25].

While some studies have shown that HIV infected individuals are not at higher risk of acquiring HEV infection than the general population [25], they are at higher risk of developing chronic HEV infection [15]. The prevalence of $\mathrm{HEV}$ infection in the general population in $\mathrm{Ni}$ geria has not been determined, however, the results of this study suggest the need to test for HEV infection in HIV positive individuals for the early diagnosis and proper management since HEV is known to be fulminant in the presence of underlying liver diseases that are common among HIV infected persons.

The participants in this study includes those who are on ART (ART experienced) as well as those who are yet to commence ART (ART Naïve). The rate of HEV IgG which is indicative of past HEV infection was higher among the ART naïve group. In addition, the two individuals who were positive for HEV IgM, an indication of recent infection was also ART Naïve individuals. This finding suggests that the use of ART may protect against acquisition of HEV infection among HIV positive individuals, probably by improving the immunity of the in- dividual (as evident in the higher mean CD4 of the ART experienced individuals). Carry et al. [26] and Keane et al. [27] have also suggested that the use of highly active antiretroviral therapy may avert chronic HEV infection. Study involving larger sample size will be required to establish this finding.

There was no association of HEV infection with low CD4 cell count and raised ALT as no significant difference in the mean CD4 cell count and mean ALT among HEV positive and HEV negative individuals. This observation is similar to the finding of Kaba et al. [15] who reported that anti-HEV prevalence did not differ significantly according to CD4 count, Cirrhosis, sex, age, mode of transmission and infection with $\mathrm{HBV} / \mathrm{HCV}$. On the other hand, Adjie et al. [17] showed a strong association of HEV positivity and high level of ALT among pig handlers in Ghana [17].

\section{What Is Already Known on This Subject}

- The rate of HEV infection varies by geographical location and between population groups.

- Hepatitis E Virus is a causative agent of acute and chronic hepatitis in severely immunocompromised patients such as organ transplant recipients and persons with HIV infection $[9,12]$.

\section{What This Study Adds to Literature}

- High burden of HEV infection among HIV positive individuals in Nigeria.

- ART may reduce the chance of acquiring HEV infection as evidence of recent infection found only among ART Naïve individuals.

- The results of this study suggest the need to test for HEV infection in HIV positive individuals for the early diagnosis and proper management since HEV is known to be fulminant in the presence of underlying liver diseases that are common among HIV.

\section{Acknowledgements}

The ART program at the University College Hospital is supported by USG PEPFAR program through a Cooperative Agreement (No: 1U2GPS001058) from the Centers for Disease Control and Prevention. Funds for antiHEV reagents were provided by the HIV/HEPATITIS project of the Department of Virology (7/225/18). The content of this article is solely the responsibility of the authors and does not necessarily represent the official views of the Centers for Disease Control and Prevention. We are grateful to all the staffs of the ART clinic and Virology laboratory for the patient enrollment and laboratory analysis. We thank immensely our patients who participated in the study.

\section{Ethical Considerations}

Approval for the study was obtained from the University 
Table 3. Pattern of HEV infection by age and gender among patients attending ART clinic at UCH, Ibadan Nigeria.

\begin{tabular}{|c|c|c|c|c|c|c|}
\hline \multirow{2}{*}{ Age } & \multicolumn{2}{|c|}{ Male } & \multicolumn{2}{|c|}{ Female } & \multicolumn{2}{|c|}{ Total } \\
\hline & No tested & No $(\%)$ Pos & No tested & No $(\%)$ Pos & No tested & No (\%) Pos \\
\hline$<20$ & 2 & 0 & 4 & 0 & 6 & 0 \\
\hline $20-29$ & 8 & 0 & 14 & $2(14.3)$ & 22 & $2(9.1)$ \\
\hline $30-39$ & 18 & $2(11.1)$ & 54 & $9(16.7)$ & 72 & $11(15.3)$ \\
\hline $40-49$ & 20 & $1(5)$ & 30 & $4(13.3)$ & 50 & $5(10.0)$ \\
\hline $50-59$ & 10 & 0 & 12 & $2(16.7)$ & 22 & $2(9.1)$ \\
\hline \multirow[t]{2}{*}{$\geq 60$} & 8 & $2(25.0)$ & 0 & 0 & 8 & $2(25.0)$ \\
\hline & 66 & $5(7.6)$ & 114 & $17(14.9)$ & 180 & $22(12.2)$ \\
\hline
\end{tabular}

of Ibadan/University College hospital ethical review board. Informed consent was obtained from all participants in the study.

\section{REFERENCES}

[1] E. H. Teshale and D. J. Hu, "Hepatitis E: Epidemiology and Prevention," World Journal of Hepatology, Vol. 3, No. 12, 2011, pp. 285-291.

[2] S. U. Emerson and R. H. Purcell, "Hepatitis E Virus," Reviews in Medical Virology, Vol. 13, No. 3, 2003, pp. 145154. doi: $10.1002 /$ rmv. 384

[3] M, Irshad, "Hepatitis E Virus: An Update on Its Molecular, Clinical and Epidemiological Characteristics," Intervirology, Vol. 42, No. 4, 1999, pp. 252-262. doi:10.1159/000024985

[4] P. Vasickova, I. Psikal, P. Kralik, F. Widen, Z. Hubalek and I. Pavlik, "Hepatitis E Virus: A Review," Veterinarni Medicina, Vol. 52, No. 9, 2007, pp. 365-384.

[5] P. Billam, F. F. Huang, Z. F. Sun, F. W. Pierson, R. B. Duncan, F. Elvinger et al., "Systematic Pathogenesis and Replication of Avian Hepatitis E Virus in Specific-Pathogen-Free Adult Chickens," Journal of Virology, Vol. 80, No. 6721, 2005, pp. 3429-3437. doi:10.1128/JVI.79.6.3429-3437.2005

[6] X. J. Meng, P. G. Halbur, T. S. Tsareva, J. D. Bruna, R. L. Royer, R. H. Purcell and S. U. Emerson, "Experimental Infection of Pigs with the Newly Identified Swine Hepatitis E Virus (Swine HEV), But Not with Human Strain of HEV," Archives of Virology, Vol. 143, No. 7, 1998, pp. 1405-1415. doi:10.1007/s007050050384

[7] C. Kasorndorkbua, P. G. Halbur, P. J. Thomas, D. K. Guenette, T. E. Toth and X. J. Meng, "Use of a Swine Bioassay and a RT-PCR Assay to Assess the Risk of Transmission of Swine Hepatitis E Virus in Pigs," Journal of Virological Methods, Vol. 101, No. 1-2, 2002, pp. 71-78.

[8] H. Okamoto, M. Takahashi, T. Nishizawa, R. Usui and E. Kobayashi, "Presence of Antibodies to Hepatitis E Virus in Japanese Pet Cats," Infection, Vol. 32, No. 1, 2004, pp. 57-58. doi:10.1007/s15010-004-3078-0

[9] M. Kaba, H. Richet, I. Ravaux, J. Moreau, I. Poizot-Mar- tin, A. Motte et al., "Hepatitis E Virus Infection in Patients Infected with the Human Immunodeficiency Virus," Journal of Medical Virology, Vol. 83, No. 10, 2011, pp. 1704-1716. doi:10.1002/jmv.22177

[10] M. S. Khuroo, V. K. Rustgi, G. J. Dawson, I. K. Mushahwar, G. N. Yattoo, S. Kamili et al., "Spectrum of Hepatitis E Virus Infection in India," Journal of Medical Virology, Vol. 43, No. 3, 1994, pp. 281-286. doi:10.1002/jmv.1890430316

[11] N. Kamar, J. Selves, J. Mansuy, L. Ouezzani, J. M. Péron, J. Guitard et al., "Hepatitis E Virus and Chronic Hepatitis in Organ-Transplant Recipients," New England Journal of Medicine, Vol. 358, No. 8, 2008, pp. 811-817. doi:10.1056/NEJMoa0706992

[12] P. le Coutre, H. Meisel, J. Hofmann, C. Röcken, G. L. Vuong, S. Neuburger et al., "Reactivation of Hepatitis E Infection in a Patient with Acute Lymphoblastic Leukaemia after Allogeneic Stem Cell Transplantation," Gut, Vol. 58, No. 5, 2009, pp. 699-702. doi:10.1136/gut.2008.165571

[13] R. H. Purcell and S. U. Emerson, "Hepatitis E: An Emerging Awareness of an Old Disease," Journal of Hepatology, Vol. 48, No. 3, 2008, pp. 494-503.

[14] M. L. Mateos, C. Camarero, E. Lasa, J. L. Teruel, N. Mir and F. Baquero, "Hepatitis E Virus: Relevance in Blood Donors and Risk Groups," Vox Sang, Vol. 76, No. 2, 1999, pp. 78-80. doi:10.1046/j.1423-0410.1999.7620078.x

[15] N. F. Crum-Cianflone, J. Curry, J. Drobeniuc, A. Weintrob, M. Landrum, A. Ganesan et al., "Hepatitis E Virus Infection in HIV-Infected Persons," Emerging Infectious Diseases, Vol. 18, No. 3, 2012, pp. 502-506. doi:10.3201/eid1803.111278

[16] S. K. Stoszek, M. Abdel-Hamid, D. A. Saleh, S. El Kafrawy, S. Narooz, Y. Hawash et al., "High Prevalence of Hepatitis E Antibodies in Pregnant Egyptian Women. Transactions of Royal Society of Tropical Medicine and $\mathrm{Hy}$ giene, Vol. 100, No. 2, 2006, pp. 95-101. doi:10.1016/j.trstmh.2004.12.005

[17] A. A. Adjei, Y. Tettey, J. T. Aviyase, C. Adu-Gyamfi, J. A. Mingle and E. T. Nartey, "Unexpected Elevated Alanine Aminotransferase, Asparte Aminotransferase Levels 
and Hepatitis E Virus Infection among Persons Who Work with Pigs in Accra, Ghana," Virology Journal, Vol. 7, No. 7, 2010, pp. 336.

http://www.virologyj.com/content/7/1/336

[18] A. B. Labrique, K. Zaman, Z. Hossain, P. Saha, M. Yunus, A. Hossain et al., "Epidemiology and Risk Factors of Incident Hepatitis E Virus Infections in Rural Bangladesh," American Journal Epidemiology, Vol. 172, No. 8, 2010, pp. 952-961. doi:10.1093/aje/kwq225

[19] S. O. Ola, G. N. Odaibo, O. D. Olaleye and E. A. Ayoola, "Hepatitis B and E Viral Infections among Nigerian Healthcare Workers," African Journal of Medicine and Medical Sciences, Vol. 41, No. 4, 2012, pp. 387-391.

[20] P. Colson, C. Dhiver and R. Gerolami, "Hepatitis E Virus as a Newly Identified Cause of Acute Viral Hepatitis during Human Immunodeficiency Virus Infection," Clinical Microbiology and Infection, Vol. 14, No. 12, 2008, pp. 1176-1180. doi:10.1111/j.1469-0691.2008.02102.x

[21] M. H. Kuniholm, R. H. Purcell, G. M. McQuillan, R. E. Engle, A. Wasley and K. E. Nelson, "Epidemiology of Hepatitis E Virus in the United States: Results from the Third National Health and Nutrition Examination Survey, 1988-1994," Journal of Infectious Diseases, Vol. 200, No. 1, 2009, pp. 48-56. doi:10.1086/599319

[22] A. Kenfak-Foguena, F. Schöni-Affolter, P. Bürgisser, A. Witteck, K. E. A. Darling, H. Kovari et al., "Hepatitis E
Virus Seroprevalence and Chronic Infections in Patients with HIV, Switzerland," Emerging Infectious Diseases, Vol. 17, No. 6, 2011, pp. 1074-1078. doi:10.3201/eid1706.101067

[23] P. Clemente-Casares, S. Pina, M. Buti, R. Jardi, M. Martín, S. Bofill-Mas and R. Girones, "Hepatitis E Virus Epidemiology in Industrialized Countries," Emerging Infectious Diseases, Vol. 9, No. 4, 2003, pp. 448-454. doi:10.3201/eid0904.020351

[24] WHO, "Guideline for Hand Hygiene in Health-Care Settings," Morbidity and Mortality Weekly Report, Vol. 51, No. RR-16, 2002.

[25] S. C. Robson, S. Adams, N. Brink, B. Woodruff and D. Bradley, "Hospital Outbreak of Hepatitis E," Lancet, Vol. 339, No. 8806, 1992, pp. 1424-1425. doi:10.1016/0140-6736(92)91250-C

[26] J. A. Curry, N. Adams and N. F. Crum-Cianflone, "Acute Hepatitis E Virus Infection in an HIV-Infected Person in the United States," Annals of Internal Medicine, Vol. 150, No. 3, 2009, pp. 226-227. doi:10.7326/0003-4819-150-3-200902030-00028

[27] F. Keane, M. Gompels, R. Bendall, R. Drayton, L. Jennings, J. Black et al., "Hepatitis E Virus Coinfection in Patients with HIV Infection," HIV Medicine, Vol. 13, 2012, pp. 83-88. 